\title{
Concentrado proteico de arroz na alimentação do jundiá (Rhamdia quelen)
}

\author{
[Rice protein concentrate in the feeding of silver catfish (Rhamdia quelen)] \\ M.O. Dalcin ${ }^{1}$, D. Pianesso ${ }^{2 *}$, V.C. Silva ${ }^{2}$, P.I. Mombach ${ }^{2}$, T.J. Adorian ${ }^{2}$, \\ J.S. Lima ${ }^{1}$, F.R. Goulart ${ }^{2}$, L.P. Silva ${ }^{3}$ \\ ${ }^{1}$ Aluno de graduação - Universidade Federal de Santa Maria - Santa Maria, RS \\ ${ }^{2}$ Aluno de pós-graduação - Universidade Federal de Santa Maria - Santa Maria, RS \\ ${ }^{3}$ Universidade Federal de Santa Maria - UFSM - Santa Maria, RS
}

\begin{abstract}
RESUMO
O objetivo do presente trabalho foi avaliar a inclusão do concentrado proteico da destilação de etanol obtido de arroz (CPA) na alimentação do jundiá. Trezentos e setenta e cinco peixes foram distribuídos em sistema de recirculação de água com 15 caixas (125L). Foram testadas três dietas $(37 \%$ PB e $3200 \mathrm{kcal} / \mathrm{kg}$ de energia digestível), sendo uma controle e duas testando a substituição da proteína da farinha de peixe em 25\% (CPA-25\%) ou 50\% (CPA-50\%) pelo CPA. Aos 30 dias, foram avaliadas as variáveis de desempenho, composição corporal e índices somáticos. Os animais submetidos ao tratamento CPA-25\% apresentaram resposta de crescimento equivalente aos que receberam o tratamento controle, mas superior aos peixes submetidos ao CPA-50\%. Não foram observadas diferenças significativas entre os tratamentos para os índices somáticos avaliados. Os animais submetidos às dietas contendo CPA apresentaram maior teor de gordura corporal. Já a deposição de gordura corporal foi superior para os peixes alimentados com CPA-25\%, e a deposição de proteína corporal menor para os alimentados com CPA-50\%. Os resultados indicam que o CPA pode substituir em até $25 \%$ a proteína da farinha de peixe, sem comprometer o crescimento dos jundiás, tendo esse nível de substituição proporcionado, inclusive, uma redução de $8 \%$ no custo da dieta.
\end{abstract}

Palavras-chave: biocombustíveis, ingredientes alternativos, quirera de arroz, nutrição de peixes

\begin{abstract}
The objective of this work was to evaluate the inclusion of protein concentrate from the distillation of ethanol from rice (CPA) in jundia feed. A total of 375 fish were distributed in water recirculation system with 15 boxes (125L). Three diets (37\% PB and 3200kcal / $\mathrm{kg}$ digestible energy), one control and two were to test for the replacement of fishmeal protein by 25 (CPA-25\%) and 50\% (CPA-50\%) by CPA. At 30 days, the variables of performance, body composition and somatic indexes were evaluated. The animals submitted to the CPA-25\% treatment presented a growth response equivalent to those that received the Control treatment, but superior to the fish submitted to the CPA-50\%. There were no significant differences between treatments for the somatic indices evaluated. Animals submitted to diets containing CPA had higher body fat content. Body fat deposition was higher for fish fed with CPA-25\% and lower body protein deposition for those fed with CPA-50\%. The results indicate that CPA can substitute up to $25 \%$ fish meal protein, without compromising the growth of jundias, and this level of substitution provided an $8 \%$ reduction in diet cost.
\end{abstract}

Keywords: biofuels, alternative ingredients, broken rice, nutrition of fish

\section{INTRODUÇÃO}

A criação de peixes constitui uma das áreas da produção animal que mais se desenvolve no

Recebido em 20 de janeiro de 2017

Aceito em 10 de março de 2017

* Autor para correspondência (corresponding author)

E-mail: pianessodirleise@gmail.com
Brasil (Matias, 2015). Para atenderem a expansão desse setor e da demanda do mercado, as técnicas de produção foram intensificadas ao longo dos últimos anos (Pezzato et al., 2009), o que exigiu a formulação de dietas completas de 
elevado valor biológico a fim de proporcionar aos peixes adequado crescimento.

Muitos estudos sobre a nutrição de peixes têm dado ênfase à substituição de fontes proteicas de origem animal por fontes proteicas vegetais, já que a farinha de peixe está se tornando cada vez mais escassa (Hardy, 2010; Lovatto et al., 2014; Lovatto, 2015). Entretanto, considerando o elevado valor biológico e a alta palatabilidade dessa fonte, torna-se um desafio encontrar ingredientes que possam substituir ou reduzir sua inclusão na dieta dos peixes. A simples substituição por fontes vegetais in natura pode ser um problema devido ao balanço inadequado de aminoácidos e à presença de antinutrientes (Rodrigues et al., 2013).

As fontes proteicas vegetais caracterizam-se pela disponibilidade constante ao longo do ano, composição homogênea e custo inferior às de origem animal. A combinação equilibrada de ingredientes proteicos alternativos apresenta maior possibilidade de sucesso na alimentação de peixes, pois, além de reduzir o impacto ambiental (excreção de nitrogênio e fósforo), torna a ração mais palatável, tendo maior aceitação pelos animais (Rodrigues et al., 2013).

Estudos indicam potencial para utilização de ingredientes de origem vegetal na dieta do jundiá. Para a recria de peixes dessa espécie $(15 \mathrm{~g})$, entretanto, os melhores índices de crescimento são obtidos quando fornecidas dietas contendo fontes de origem animal combinadas com farelo de soja (Lazzari et al., 2008). Ao avaliarem diferentes fontes proteicas para 0 jundiá, Lazzari et al. (2006) encontraram maior fator de condição $(0,7-1,0)$ em dietas contendo farinha de carne e ossos ou farinha de peixe associada com farelo de soja. A associação das fontes proteicas de farelo de soja e levedura de cana também proporcionou maior fator de condição $(0,9-1,07)$ para essa espécie (Coldebella e Radünz Neto, 2002). Diante disso, a utilização de ingredientes alternativos na dieta dessa espécie poderá possibilitar redução dos custos com a fabricação de ração, porém esses ingredientes precisam ser avaliados em ensaios biológicos para se conhecerem os efeitos e os níveis adequados de inclusão na dieta.

O uso de quirera e de farelo de arroz para geração de etanol é motivado pela sua ampla disponibilidade e pelo baixo custo na região Sul do país. Porém, a geração de resíduos intermediários nesse processo pode ser um entrave para o sucesso da biorrefinaria arrozeira, já que nesse processo são gerados aproximadamente $77 \%$ de resíduo úmido e 3,6\% de resíduo seco (dados não publicados). Nesse cenário, estudos de aplicabilidade desses resíduos na nutrição de peixes são alternativas factíveis, que podem minimizar impactos ambientais, contribuir para a sustentabilidade da cadeia arrozeira e agregar valor produtivo à piscicultura. Diante disso, o presente estudo foi desenvolvido com o objetivo de estudar a possibilidade de substituir a farinha de peixe pelo resíduo de etanol obtido da quirera de arroz.

\section{MATERIAL E MÉTODOS}

O presente trabalho foi desenvolvido no Laboratório de Piscicultura do Departamento de Zootecnia da Universidade Federal de Santa Maria, após aprovação do Comitê Interno de Ética em Experimentação Animal da UFSM, sob n²789270616.

A obtenção do CPA foi realizada na Usina Experimental do Colégio Politécnico da UFSM. A matéria-prima (quirera de arroz) foi moída em moinho de martelo, obtendo-se granulometria média de $180 \mu \mathrm{m}$. Ao material farelado foi adicionada água na proporção de 1:10 (peso/volume). A solução foi aquecida a $90^{\circ} \mathrm{C}$ com agitação constante por 30 minutos, o pH da solução foi corrigido para 6,5 com HCL $1 \mathrm{~N}$ e adicionou-se a enzima $\alpha$-Amilase (Termamyl $2 x$ - Novozymes/Lote: AYVD0065), que atuou por 30 minutos. Na sequência, a temperatura e o pH foram ajustados para $60^{\circ} \mathrm{C}$ e 4,5 respectivamente, e foi adicionada a enzima amiloglicosidade (AMG 300L Novozymes/Lote:AMS30084), que atuou por mais 30 minutos.

A fase sólida foi separada por filtragem, em peneira de $300 \mu \mathrm{m}$. A massa obtida foi novamente dispersa em água a $60^{\circ} \mathrm{C}$, na proporção de 3:1, e filtrada na mesma malha, congelada e liofilizada (Solab/SL -404) a uma temperatura de $-45^{\circ} \mathrm{C}$, pressão $-775 \mathrm{Hg}$, por 50 horas. O material seco foi moído em micromoinho de facas (granulometria média de $200 \mu \mathrm{m})$ e armazenado em temperatura média de $-18^{\circ} \mathrm{C}$, para posterior utilização.

O experimento foi conduzido em sistema de recirculação de água, constituído por reservatório 
principal de $2000 \mathrm{~L}, 15$ caixas de $125 \mathrm{~L}$ de volume útil, com entrada e saída de água independentes, dois filtros biológicos com pedra britada e caixa de decantação. Além disso, a temperatura do local do experimento foi controlada por meio de climatizador de ar de 12000BTUs.

Inicialmente, os peixes passaram por período de 10 dias de adaptação às instalações experimentais, quando receberam ração comercial com $42 \%$ de proteína bruta $(\mathrm{PB})$. $\mathrm{Na}$ biometria inicial, 375 juvenis de jundiá (em média $3,56 \mathrm{~g}$ ) foram selecionados e distribuídos em 15 unidades experimentais (25 peixes/caixa).

As dietas experimentais foram formuladas para atender as exigências de $37 \%$ de $\mathrm{PB}$, conforme Meyer e Fracalossi (2004) e cerca de 3200kcal ED/kg e aminoácidos, conforme Montes-Girao e Fracalossi (2006). As exigências dos aminoácidos essenciais foram atendidas com a formulação utilizada, sendo necessário suplementar apenas com metionina. A proteína da farinha de peixe $(52,21 \%$ PB) foi substituída parcialmente pela proteína do concentrado proteico de arroz - CPA $(61,03 \%$ PB; $88,06 \%$ de matéria seca (MS); 2,02\% de matéria mineral (MM); 36,59\% de fibra em detergente neutro (FDN) e $9,07 \%$ de gordura), nas proporções de $0 \%$ (dieta controle); $25 \%$ e $50 \%$ (Tab. 1 ).

As dietas experimentais foram confeccionadas no Laboratório de Piscicultura (UFSM). Os ingredientes secos (moídos e pesados) foram homogeneizados manualmente e, posteriormente, adicionaram-se o óleo e a água, e, em seguida, eles foram peletizados. As rações foram secas em estufa $\left(50^{\circ} \mathrm{C}\right)$, por 24 horas.

As dietas experimentais foram oferecidas aos peixes até saciedade aparente, três vezes ao dia ( 8 horas, $13 \mathrm{~h}$ e 17h). Além disso, foram realizadas sifonagens duas vezes ao dia, para remoção de fezes e eventuais sobras de ração.

Foi mensurada diariamente a temperatura $\left(24,8 \pm 1,27^{\circ} \mathrm{C}\right)$ com termômetro. Semanalmente, foram determinados o oxigênio dissolvido $\left(7 \pm 0,5 \mathrm{mg} \quad \mathrm{L}^{-1} \quad \mathrm{O}^{2}\right), \quad$ o $\quad \mathrm{pH} \quad(7,63 \pm 0,25), \quad$ a alcalinidade $\left(44 \pm 12,96 \mathrm{mg} \mathrm{L}^{-1} \mathrm{CaCO}_{3}\right)$, a dureza $\left(34 \pm 11,2 \mathrm{mg} \mathrm{L}^{-1} \mathrm{CaCO}_{3}\right)$, a amônia $(0,19 \pm 0,13 \mathrm{mg}$ $\left.\mathrm{L}^{-1} \mathrm{~N}-\mathrm{NH}_{3}\right)$ e o nitrito $\left(0,01 \pm 0,01 \mathrm{mg} \mathrm{L}^{-1} \mathrm{~N}_{-} \mathrm{NO}_{2}\right)$ da água do sistema de recirculação, pelo método colorimétrico, utilizando-se o kit colorimétrico Alfakit $^{\circledR}$. Os valores encontrados para os parâmetros mensurados se encontram dentro da faixa ideal para cultivo de jundiá (Baldisserotto e Radünz Neto, 2004).

No início do experimento, os peixes foram pesados e medidos individualmente para obtenção do peso médio inicial e dos valores de comprimento padrão e total. Aos 30 dias de experimento, foi realizada biometria para coleta de dados de desempenho. Para tanto, os peixes foram submetidos a jejum de 12 horas e anestesiados com benzocaína $(100 \mathrm{mg} / \mathrm{L})$ (Anziliero et al., 2008). Com base nos dados coletados, foram estimados os seguintes parâmetros: consumo (g); conversão alimentar aparente (CAA): ração consumida/peso obtido; biomassa total (BT); peso médio final (g); comprimento total $(\mathrm{cm})$; ganho de peso $(\mathrm{g})$ : $\mathrm{GP}=$ (peso final - peso inicial); taxa de crescimento específico (TCE): [(ln (peso final) - ln (peso inicial)) /dias] x 100, sendo: $\mathrm{In}=$ logaritmo neperiano; sobrevivência. No final do período experimental, foram abatidos cinco animais/tratamento para determinação dos índices somáticos: índice hepato-somático (IHS) (\%): (peso fígado/peso do peixe inteiro) x 100; índice digestivo-somático (IDS) (\%): (peso do trato digestório/peso do peixe inteiro) x 100; quociente intestinal (QI): (comprimento do trato digestório/comprimento total do peixe); rendimento de carcaça (\%): $\mathrm{RC}=$ ((peso eviscerado com cabeça e brânquias)/(peso inteiro) $)^{*} 100$. Além disso, foram abatidos cinco animais por tratamento para determinação da composição centesimal: proteína bruta (método de micro-Kjeldahl, usando-se o fator $\mathrm{N}$ x 6,25), teor de umidade e o conteúdo de cinzas, determinados de acordo com AOAC (Official..., 1995). A gordura foi extraída e quantificada seguindo o método de Bligh e Dyer (1959).

A retenção de nutrientes foi calculada por meio das equações:

deposição de proteína corporal $(\mathrm{g}): \mathrm{DPC}=[\mathrm{Pf} *$ $(\% \mathrm{PBCf} / 100)]-[\mathrm{Pi} *(\% \mathrm{PBCi} / 100)]$;

deposição de gordura corporal $(\mathrm{g}): \mathrm{DGC}=[\mathrm{Pf} *$ $(\% \mathrm{GCf} / 100)]-[\mathrm{Pi} *(\% \mathrm{GCi} / 100)]$;

em que: $\mathrm{PBC}=$ proteína corporal inicial; $\mathrm{PBCf}=$ proteína corporal final; $\mathrm{GCi}$ : gordura corporal inicial; GCf: gordura corporal final. 
Tabela 1. Composição das dietas experimentais

\begin{tabular}{|c|c|c|c|}
\hline \multirow{2}{*}{ Conteúdo } & \multicolumn{3}{|c|}{ Dietas $^{\top}$} \\
\hline & Controle & CPA- $25 \%$ & CPA- $50 \%$ \\
\hline \multicolumn{4}{|l|}{ Ingredientes $(\%)$} \\
\hline $\mathrm{CPA}$ & 0,00 & 8,55 & 17,12 \\
\hline Farinha de peixe $^{2}$ & 40,00 & 30,00 & 20,00 \\
\hline $\mathrm{CPS}^{3^{3}}$ & 26,20 & 26,20 & 26,20 \\
\hline Amido & 21,96 & 20,67 & 19,36 \\
\hline Óleo de peixe & 0,00 & 1,00 & 2,00 \\
\hline Óleo de soja & 2,10 & 2,10 & 2,10 \\
\hline Mistura vitamínica e mineral $^{4}$ & 3,00 & 3,00 & 3,00 \\
\hline Fosfato bicálcico & 1,00 & 1,30 & 1,50 \\
\hline Cloreto de sódio $(\mathrm{NaCl})$ & 0,25 & 0,25 & 0,25 \\
\hline Calcário calcítico & 1,00 & 0,85 & 0,65 \\
\hline Metionina & 0,20 & 0,20 & 0,20 \\
\hline Celulose $^{5}$ & 4,29 & 5,88 & 7,62 \\
\hline \multicolumn{4}{|l|}{ Composição proximal $(\%)^{6}$} \\
\hline Proteína bruta & 37,01 & 37,01 & 37,02 \\
\hline Gordura & 6,95 & 6,90 & 6,84 \\
\hline Energia digestível $(\mathrm{kcal} / \mathrm{kg})^{7}$ & 3200,23 & 3200,24 & 3200,28 \\
\hline Cálcio & 0,82 & 0,81 & 0,76 \\
\hline Fósforo & 0,75 & 0,71 & 0,66 \\
\hline \multicolumn{4}{|c|}{ Composição de aminoácidos essenciais na dieta (\%) } \\
\hline Histidina & 0,95 & 0,97 & 1,00 \\
\hline Arginina & 3,16 & 3,26 & 3,37 \\
\hline Treonina & 1,80 & 1,73 & 1,67 \\
\hline Valina & 1,99 & 2,06 & 2,13 \\
\hline Metionina + cistina & 1,40 & 1,43 & 1,45 \\
\hline Isoleucina & 1,72 & 1,81 & 1,90 \\
\hline Leucina & 3,06 & 3,11 & 3,15 \\
\hline Fenilalanina & 1,89 & 1,96 & 2,04 \\
\hline Lisina & 2,60 & 2,37 & 2,15 \\
\hline Triptofano $^{8}$ & - & - & - \\
\hline
\end{tabular}

Dietas: controle - sem inclusão do concentrado proteico de arroz; CPA 25 e $50 \%$ - substituição de 25 e $50 \%$ da proteína da farinha de peixe pela proteína do concentrado proteico de arroz.

${ }^{2}$ Resíduo da filetagem de tilápia - Copisces ${ }^{\circledR}$, Toledo-PR.

${ }^{3}$ Concentrado proteico de soja (60\% proteína bruta) - Selecta ${ }^{\circledR}$, Goiânia-GO.

${ }^{4}$ Composição da mistura vitamínica e mineral $(\mathrm{kg})$ : ácido fólico: 997,50mg; ácido pantotênico: 9975,00mg; biotina: 159,60mg; cobalto: $39,90 \mathrm{mg}$; cobre: $2800,00 \mathrm{mg}$; etoxiquina: $24,78 \mathrm{~g}$; ferro $19,62 \mathrm{~g}$; iodo: $120,00 \mathrm{mg}$; manganês: $5200,00 \mathrm{mg}$; niacina 19,95g; selênio: 119,70mg; vit. A 1995000UI; vit. B1 4987,50mg; vit. B12 5985,00mg; vit. B2 4987,50g; vit. B6 4987,50mg; vit. C 70,00g; vit. D3 198000,05UI; vit. E 19950,00UI; vit. K 997,50mg; zinco 28,00g - Nutron ${ }^{\mathbb{B}}$ (Cargil), Campinas-SP.

${ }^{5}$ Synth ${ }^{\circledR}$, Diadema/SP.

${ }^{6}$ Calculada com base nas análises dos ingredientes.

${ }^{7}$ Energia digestível calculada com base nos ingredientes $=\left[\left(\mathrm{PB}^{*} 5640 \mathrm{kcal} / \mathrm{kg} * 0,9\right)+(\mathrm{EE} * 9510 \mathrm{kcal} / \mathrm{kg}\right.$ $* 0,85)+(\mathrm{CSDN} * 4110 \mathrm{kcal} / \mathrm{kg} * 0,50)] / 100(\mathrm{JOBLING}, 1983)$.

${ }^{8}$ Não calculado.

A viabilidade econômica das dietas foi determinada por meio da multiplicação do custo total dos ingredientes na dieta pela conversão alimentar dos peixes submetidos aos tratamentos (custo por $\mathrm{kg}$ da dieta). $\mathrm{O}$ custo por $\mathrm{kg}$ da carcaça foi calculado mediante a multiplicação do rendimento da carcaça $(\mathrm{RC} \%)$ de cada tratamento pelo custo total dos ingredientes.
O delineamento experimental utilizado foi $\mathrm{o}$ inteiramente ao acaso, com três tratamentos e cinco repetições. Todos os dados obtidos foram submetidos a teste de normalidade (ShapiroWilk), sendo considerados de distribuição normal aqueles que apresentaram $\mathrm{P}>0,05$. Os dados foram submetidos à análise de variância (ANOVA) e as médias foram comparadas pelo teste de Tukey, ao nível de 5\% de significância. 
O modelo matemático está descrito a seguir:

$Y_{i j}=m+t_{i}+e_{i j}$, em que:

$\mathrm{Y}_{\mathrm{ij}}=$ valor observado da variável $\mathrm{Y}$ na unidade experimental que recebeu o tratamento i na repetição j;

$\mathrm{m}=$ constante;

$\mathrm{t}_{\mathrm{i}}=$ efeito do tratamento $\mathrm{i}$;

$\mathrm{e}_{\mathrm{ij}}=$ erro experimental.

\section{RESULTADOS E DISCUSSÃO}

Os resultados deste estudo antecipam informações relevantes da utilização do concentrado proteico de arroz (CPA), como ingrediente alternativo e de elevado valor biológico para a alimentação do jundiá.

A substituição da proteína da farinha de peixe por CPA influenciou significativamente os parâmetros zootécnicos dos jundiás (Tab. 2). O consumo de ração foi superior para os peixes alimentados com a dieta contendo CPA-25\%. A conversão alimentar aparente (CAA) foi menor $(\mathrm{P}<0,0001)$ para os animais alimentados com as dietas controle e CPA- $25 \%$ e maior para os peixes alimentados com a dieta CPA- 50\%. Sugere-se que, na dieta CPA- $50 \%$, podem ter ocorrido perdas de ração, o que levou à superestimação do consumo e refletiu em maior CAA. Além disso, resultados obtidos por Tyska et al. (2013), com inclusão de concentrados proteicos vegetais na dieta do jundiá, proporcionaram valores de CAA $(0,80-1,85)$ similares aos valores encontrados no presente estudo.

A biomassa foi superior para os jundiás alimentados com as dietas controle e CPA-25\%. Esse mesmo comportamento foi observado para as variáveis peso final (PF) e comprimento total (CT) (Tab. 2). O ganho de peso (GP) e a taxa de crescimento específico (TCE) foram superiores para os peixes alimentados com a dieta controle, e não diferiram do ganho apresentado pelos animais alimentados com a dieta CPA $-25 \%$ (Tab. 2).

Não foram observadas diferenças $(\mathrm{P}=0,6186)$ na sobrevivência dos peixes alimentados com as dietas experimentais (Tab. 2).

Ao se analisarem as variáveis zootécnicas descritas na Tab. 2, observa-se que a substituição de $50 \%$ da proteína da farinha de peixe pela proteína do CPA afetou negativamente a maioria dos parâmetros de desempenho dos jundiás. Estudos demonstram que há efeitos sinérgicos de fontes proteicas quando usadas em conjunto, e esses efeitos estão relacionados com as proporções combinadas das fontes (Martinelli, 2013). Sugere-se que as dietas controle e CPA$25 \%$ proporcionaram melhor sincronismo nutricional com disponibilidade mais estável dos nutrientes advindos da dieta, o que reflete positivamente no desempenho dos animais.

Tabela 2. Desempenho de jundiás alimentados com dietas contendo níveis de substituição da proteína da farinha de peixe por concentrado proteico de arroz

\begin{tabular}{cccccc}
\hline Variáveis* & \multicolumn{3}{c}{ Dietas $(\%)$} & & ANOVA \\
\cline { 2 - 4 } & Controle & CPA $-25 \%$ & CPA $-50 \%$ & epm $^{z}$ & $\begin{array}{c}\text { ANor de P) } \\
\text { (valor }\end{array}$ \\
\hline Consumo $(\mathrm{g})$ & $258,26 \mathrm{~b}$ & $317,58 \mathrm{a}$ & $259,18 \mathrm{~b}$ & 8,22 & $<0,0001$ \\
CAA & $1,56 \mathrm{a}$ & $1,34 \mathrm{a}$ & $2,57 \mathrm{~b}$ & 0,16 & $<0,0001$ \\
Biomassa $(\mathrm{g})$ & $333,36 \mathrm{a}$ & $286,87 \mathrm{a}$ & $220,50 \mathrm{~b}$ & 14,47 & 0,0004 \\
PF $(\mathrm{g})$ & $14,24 \mathrm{a}$ & $12,48 \mathrm{a}$ & $9,52 \mathrm{~b}$ & 0,61 & 0,0005 \\
CT $(\mathrm{cm})$ & $11,76 \mathrm{a}$ & $11,41 \mathrm{a}$ & $10,49 \mathrm{~b}$ & 0,17 & 0,0006 \\
GP $(\mathrm{g})$ & $9,06 \mathrm{a}$ & $7,82 \mathrm{ab}$ & $5,71 \mathrm{~b}$ & 0,52 & 0,0135 \\
TCE & $4,16 \mathrm{a}$ & $3,87 \mathrm{ab}$ & $3,18 \mathrm{~b}$ & 0,15 & 0,0154 \\
Sobrevivência (\%) & 100 & 99,20 & 99,20 & 0,36 & 0,6186 \\
\hline
\end{tabular}

Médias ( $\mathrm{n}=5)$ seguidas por letras diferentes e sobrescritas $\left({ }^{\mathrm{a}, \mathrm{b}}\right)$ na linha diferem estatisticamente pelo teste de Tukey $(\mathrm{P}<0,05) .{ }^{*} \mathrm{CAA}=$ conversão alimentar aparente, $\mathrm{PF}=$ peso final, $\mathrm{CT}=$ comprimento total, $\mathrm{GP}=$ ganho de peso, $\mathrm{TCE}=$ taxa de crescimento específico. ${ }^{ }$epm $=$erro padrão da média.

Peso médio inicial $=3,56 \pm 0,6 \mathrm{~g}$ e comprimento médio inicial $=7,07 \pm 0,46 \mathrm{~cm}$. 
Após analisar mais profundamente o relato apresentado no trabalho, pode-se dizer que fontes proteicas vegetais têm maior velocidade de digestão, nesse caso, levando a um assincronismo na digestão/absorção dos nutrientes da dieta, o que acarreta maior desaminação e aproveitamento dos esqueletos carbonados como fonte de reserva energética. Essa hipótese é levantada pela observação do maior teor de gordura apresentado pelos peixes dos tratamentos CPA-25\% e CPA-50\%. Segundo Nelson e Cox (2004), quando a proteína é desaminada, os esqueletos de carbono são utilizados no ciclo de Krebs, para produção de energia. Se houver excesso de cadeias de carbono e consequente excesso de produção de energia, esta será armazenada na forma de gordura.

O menor desempenho dos peixes quando são utilizadas dietas com níveis crescentes de fontes proteicas vegetais já foi documentado em muitos estudos (Deng et al., 2006; Lazzari et al., 2006; Nagel et al., 2012). Porém, no presente estudo, observou-se que é possível substituir pelo menos $25 \%$ da proteína da farinha de peixe pela proteína do CPA, sem comprometer o desempenho. É consenso que a substituição das fontes proteicas de origem animal, principalmente a farinha de peixe, por proteínas de origem vegetal, é uma necessidade atual, que visa garantir a consolidação dos sistemas produtivos na aquicultura (Fuertes et al., 2013). Além disso, o jundiá, por ser uma espécie onívora, tem boa aceitação de ingredientes vegetais na dieta. Estudos com essa espécie indicam que há potencial de substituição parcial da proteína de origem animal por concentrados proteicos de farelo de girassol e crambe (Lovatto et al., 2014) e por concentrado proteico de farelo de semente de abóbora (Lovatto, 2015). Os resultados aqui apresentados aliam-se aos estudos citados, confirmando-se, assim, a possibilidade de uso de fontes proteicas vegetais na dieta de jundiás. Alterações morfológicas e fisiológicas podem ser detectadas pela mensuração dos índices somáticos, que auxiliam

na indicação de adaptações do animal em relação ao fornecimento de diferentes dietas. No presente estudo, não foram observadas diferenças significativas $(\mathrm{P}>0,05)$ nos índices somáticos IHS, IDS e QI dos peixes (Tab. 3). De acordo com Pedron et al. (2006), os índices somáticos são indicativos de adaptação do trato gastrointestinal ao alimento ingerido. Os resultados obtidos para essas variáveis sugerem que os níveis de CPA utilizados não causaram modificação na estrutura e/ou na capacidade absortiva do sistema digestório. Também não houve efeito $(\mathrm{P}>0,05)$ das dietas experimentais sobre o rendimento de carcaça dos peixes.

$\mathrm{Na}$ Tab. 4, encontram-se os resultados de composição e deposição de nutrientes corporais dos jundiás. Os peixes alimentados com as dietas contendo 25 e $50 \%$ de CPA apresentaram maior teor de gordura corporal $(\mathrm{P}<0,0001)$. Além disso, os jundiás alimentados com a dieta CPA-25\% apresentaram maior deposição de gordura corporal (DGC) e os animais que receberam a dieta CPA-50\% obtiveram menor deposição de proteína corporal (DPC) $(\mathrm{P}=0,0156)$. Não foram observadas diferenças significativas $(\mathrm{P}>0,05)$ no teor de proteína, cinzas e umidade corporal dos peixes submetidos às dietas experimentais.

Tabela 3. Índices somáticos de jundiás alimentados com dietas contendo níveis de substituição da proteína da farinha por concentrado proteico de arroz

\begin{tabular}{|c|c|c|c|c|c|}
\hline \multirow{2}{*}{ Variáveis* } & \multicolumn{3}{|c|}{ Dietas (\%) } & \multirow{2}{*}{$\mathrm{epm}^{\mathrm{z}}$} & \multirow{2}{*}{$\begin{array}{l}\text { ANOVA } \\
\text { (valor de P) }\end{array}$} \\
\hline & Controle & CPA- $25 \%$ & CPA- $50 \%$ & & \\
\hline IHS (\%) & 1,51 & 1,42 & 1,57 & 0,07 & 0,7049 \\
\hline IDS (\%) & 3,91 & 3,91 & 4,20 & 0,11 & 0,5207 \\
\hline QI (\%) & 1,21 & 1,36 & 1,25 & 0,05 & 0,5318 \\
\hline $\mathrm{RC}(\%)$ & 87,66 & 87,44 & 87,16 & 0,25 & 0,7426 \\
\hline
\end{tabular}

Médias $(n=5)$ seguidas por letras diferentes e sobrescritas $\left({ }^{a, b}\right)$ na linha diferem estatisticamente pelo teste de Tukey $(\mathrm{P}<0,05) .{ }^{*} \mathrm{IHS}=$ índice hepato-somático, IDS = índice digestivo-somático, $\mathrm{QI}=$ quociente intestinal e $\mathrm{RC}=$ rendimento de carcaça. epm $\mathrm{z}^{\mathrm{z}}$ erro padrão da média. 


\section{Dalcin et al.}

Tabela 4. Composição centesimal e deposição de nutrientes de jundiás alimentados com dietas contendo níveis de substituição da proteína da farinha por concentrado proteico de arroz

\begin{tabular}{|c|c|c|c|c|c|}
\hline \multirow{2}{*}{ Variáveis* } & \multicolumn{3}{|c|}{ Dietas $(\%)$} & \multirow{2}{*}{$\mathrm{epm}^{\mathrm{z}}$} & \multirow{2}{*}{$\begin{array}{c}\text { ANOVA } \\
\text { (valor de P) }\end{array}$} \\
\hline & Controle & CPA- $25 \%$ & CРA- $50 \%$ & & \\
\hline Proteína (\%) & 15,65 & 15,27 & 14,94 & 0,21 & 0,4305 \\
\hline Umidade (\%) & 77,69 & 77,42 & 77,24 & 0,17 & 0,6036 \\
\hline Cinzas $(\%)$ & 3,04 & 2,89 & 2,94 & 0,08 & 0,7600 \\
\hline Gordura (\%) & $4,22^{\mathrm{b}}$ & $6,35^{\mathrm{a}}$ & $6,07^{\mathrm{a}}$ & 0,28 & $<0,0001$ \\
\hline $\mathrm{DPC}(\mathrm{g})$ & $1,53^{\mathrm{a}}$ & $1,29^{\mathrm{ab}}$ & $0,94^{\mathrm{b}}$ & 0,09 & 0,0156 \\
\hline DGC (g) & $0,42^{\mathrm{b}}$ & $0,61^{\mathrm{a}}$ & $0,45^{\mathrm{b}}$ & 0,03 & 0,0035 \\
\hline
\end{tabular}

Médias $(\mathrm{n}=5)$ seguidas por letras diferentes e sobrescritas $\left({ }^{\mathrm{a}, \mathrm{b}}\right)$ na linha diferem estatisticamente pelo teste de Tukey $(\mathrm{P}<0,05) .{ }^{*} \mathrm{DPC}=$ deposição de proteína corporal e $\mathrm{DGC}=$ deposição de gordura corporal. ${ }^{\mathrm{Z}}$ epm= erro padrão da média.

Considerando-se que as dietas experimentais foram similares quanto à composição nutricional, infere-se que as diferenças observadas na composição corporal dos peixes são devido às diferentes proporções e combinações dos ingredientes que compuseram as dietas. Apesar do maior teor $(6,35 \%)$ e deposição de gordura corporal $(0,61 \%)$, apresentado pelos peixes submetidos às dietas contendo níveis (25 e 50\%) do CPA, esses valores são similares aos resultados obtidos em outros estudos, que testaram fontes vegetais para a mesma espécie 9,13-12,83\% (Lovatto et al., 2014); 3,6-6,5\%, (Lazzari et al., 2006). Além disso, as reservas corporais dos peixes na fase inicial de crescimento são fundamentais para a manutenção metabólica nessa fase de vida, principalmente quando enfrentam alguma situação adversa.
A análise de viabilidade econômica da substituição da proteína da farinha de peixe pelo CPA na dieta do jundiá (Tab. 5) demonstrou que, em produção de larga escala, há economicidade de $\mathrm{R} \$ 0,13$ para cada quilo de ração (R\$130,00/ton) quando é feita a substituição de $25 \%$ da proteína da farinha peixe pela proteína do CPA. Isso representa um custo $8 \%$ menor $/ \mathrm{kg}$ na produção da dieta CPA-25\% em comparação com a produção da mesma quantidade da dieta padrão. O custo por $\mathrm{kg}$ da dieta $\mathrm{CPA}-50 \%$ foi maior $(\mathrm{R} \$ 112,18 / \mathrm{kg})$ devido à maior conversão alimentar apresentada pelos peixes submetidos a esse tratamento. Porém, para produzir $1 \mathrm{~kg}$ de ração CPA-50\%, o custo é $\mathrm{R} \$ 0,16$ menor em relação à dieta controle, sendo uma alternativa viável para a redução de custos em dietas para peixes.

Tabela 5. Viabilidade econômica da substituição da proteína da farinha de peixe por concentrado proteico de arroz

\begin{tabular}{ccccc}
\hline & \multicolumn{4}{c}{ Dietas experimentais } \\
\hline & $(\mathrm{R} \$ / \mathrm{kg})$ & Controle & CPA-25\% & CPA-50\% \\
\hline Custo por kg da dieta & - & 68,53 & 58,49 & 112,18 \\
Custo por kg da carcaça & - & 38,26 & 38,16 & 38,04 \\
\hline CPA & Custo por ingrediente para produzir 1 kg de ração \\
\hline Farinha de peixe & 0,50 & 0 & 0,04275 & 0,0856 \\
CPS & 1,82 & 0,728 & 0,546 & 0,364 \\
Amido & 2,25 & 0,5895 & 0,5895 & 0,5895 \\
Óleo de peixe & 1,00 & 0,2196 & 0,2067 & 0,1936 \\
Óleo de soja & 5,00 & 0 & 0,005 & 0,1 \\
Mistura vitamínica e mineral & 3,00 & 0,063 & 0,063 & 0,063 \\
Fosfato bicálcico & 4,00 & 0,12 & 0,12 & 0,12 \\
Cloreto de sódio (NaCl) & 0,020 & 0,0002 & 0,00026 & 0,0003 \\
Calcário calcítico & 0,8 & 0,002 & 0,002 & 0,02 \\
Metionina & 0,010 & 0,0001 & 0,000085 & 0,00065 \\
Celulose & 25,00 & 0,05 & 0,05 & 0,05 \\
Total & 1,00 & 0,0429 & 0,0588 & 0,0762 \\
\end{tabular}




\section{CONCLUSÃO}

A proteína da farinha de peixe pode ser substituída em até $25 \%$ pela proteína do concentrado proteico de arroz, sem comprometimento ao desenvolvimento dos jundiás e com menor custo de produção em relação à dieta controle. A dieta CPA- $50 \%$ foi insatisfatória para o crescimento adequado dos peixes.

\section{REFERÊNCIAS}

ANZILIERO, D.; KREUTZ, C.L.; BARCELLOS, G.J.L. Avaliação de quatro diferentes anestésicos para sua utilização no manejo de jundiás (Rhamdia quelen). In: CONGRESSO BRASILEIRO DE MEDICINA VETERINÁRIA, 35., 2008, Gramado. Anais... Gramado, Rio Grande do Sul: Conbravet, 2008. Disponível em: <http://www.sovergs.com.br/ conbravet2008/anais/cd/resumos/R0813-1.pdf>. Acessado em: 19 de ago. 2016.

BALDISSEROTTO, B.; RADÜNZ NETO, J. Criação de jundiá. Santa Maria: UFSM, 2004. $23 \mathrm{p}$.

BLIGH, E.G.; DYER, W.J. Rapid method of total lipid extraction and purification. $J$. Biochem. Physiol., v.37, p.911-917, 1959.

COLDEBELLA, I.J.; RADÜNZ NETO, J. Farelo de soja na alimentação de alevinos de jundiá (Rhamdia quelen). Ciênc. Rural, v.32, p.499503, 2002.

DENG, J.; MAI, K.; AI, Q. et al. Effects of replacing fish meal with soy protein concentrate on feed intake and growth of juvenile Japanese flounder, Paralichthys olivaceus. Aquaculture, v.258, p.503-513, 2006.

FUERTES, J.B.; CELADA, J.D.; CARRAL, J.M. et al. Replacement of fish meal by pea protein concentrate in practical diets for juvenile crayfish (Pacifastacus leniusculus Dana, Astacidae) from the onset of exogenous feeding. Aquaculture, v.388-391, p. 159-164, 2013.

HARDY, R.W. Utilization of plant proteins in fish diets: effects of global demand and supplies of fishmeal. Aquacult. Res., v.41, p.770-776, 2010 .

Arq. Bras. Med. Vet. Zootec., v.70, n.1, p.306-314, 2018
LAZZARI, R.; RADÜNZ NETO, J.; EMANUELLI T. et al. Diferentes fontes protéicas para a alimentação do jundiá (Rhamdia quelen). Ciênc. Rural, v.36, p.240-246, 2006.

LAZZARI, R.; RADÜNZ NETO, J.R.; PEDRON, F.A. et al. Desempenho e composição dos filés de jundiás (Rhamdia quelen) submetidos a diferentes dietas na fase de recria. Arq. Bras. Med. Vet. Zootec., v.60, p. 477-484, 2008.

LOVATto, N. M. Concentrado proteico de semente de abóbora (Cucurbita moschata) na nutrição do jundiá. 2015. 133f. Tese (Doutorado em Zootecnia) - Universidade Federal de Santa Maria, Santa Maria, RS.

LOVATTO, N.M.; SILVA, L.P.; LOUREIRO, B.B.; et al. Efeitos de dietas contendo concentrados proteicos vegetais no desempenho e atividade de enzimas digestivas de jundiá (Rhamdia quelen). Semin-Cienc. Agrar., v.35, p.1071-1082, 2014.

MARTINELLI, S.G. Dinâmica digestiva proteica e resposta de desempenho em jundiá (Rhamdia quelen). 2013. 63f. Dissertação (Mestrado em Zootecnia) - Universidade Federal de Santa Maria, Santa Maria, RS.

MATIAS, F. Aquicultura brasileira é destaque em evento da FAO na Turquia. Disponível em: $<$ http://www.mpa.gov.br/component/content/arti cle id=2706 $>$. Acessado em: 23 fev. 2017.

MEYER, G.; FRACALOSSI, D.M. Protein requirement of jundiá fingerlings, Rhamdia quelen, at two dietary energy concentrations. Aquaculture, v.240, p.331-343, 2004.

MONTES-GIRAO, P.J.; FRACALOSSI, D.M. Dietary lysine requirement as basis to estimate the essential dietary amino acid profile for jundiá, Rhamdia quelen. J. World Aquacult. Soc., v.37, p.388-396, 2006.

NAGEL, F.; DANWITZA, A.V.; TUSCHEA, K. et al. Nutritional evaluation of rapeseed protein isolate as fish meal substitute for juvenile turbot (Psetta maxima L.) - Impact on growth performance, body composition, nutrient digestibility and blood physiology. Aquaculture, v.356-357, p.357-364, 2012.

NELSON, D.L.; COX, M.M. Lehninger: principles of biochemistry. 4.ed. New York: W.H. Freeman, 2004. 1130p. 
OFFICIAL methods of analyses. 16.ed. Washington: AOAC, 1995. 1018p.

PEDRON, F.A. Fibra na alimentação do jundiá (Rhamdia quelen). 2006, 64f. Dissertação (Mestrado em Zootecnia) - Universidade Federal de Santa Maria, Santa Maria, RS.

PEZZATO, L.E.; BARROS, M.M.; FURUYA, W.M. Valor nutritivo dos alimentos utilizados na formulação de rações para peixes tropicais. Rev. Bras. Zootec., v.38, p.43-51, 2009.
RODRIGUES, A.P.O.; BERGAMIN, G.T.; SANTOS, V.R.V. Nutrição e alimentação de peixes. In: RODRIGUES, A.P.O. et al. (Orgs.). Piscicultura de água doce: multiplicando conhecimentos. Brasília: Embrapa, 2013. cap.6, p.171-213.

TYSKA, D.; MALLMANN, C.A.; CORRÊIA, $\mathrm{V}$. et al. Concentrados proteicos vegetais na alimentação de jundiás (Rhamdia quelen). Ciênc. Rural, v.43, p.1251-1257, 2013. 